\title{
HET „INCORPORATED” INSTITUUT VAN ACTUARIES TE LONDEN, EN DE WERKKRING VAN DEN ACTUARY.
}

Ia science des Actuaires a pour objet la finance, les assurances et la statistique.

Chardon, Théorie mathémalique des opérations financières.

In 1877 had ik het genoegen de rij van mijne artikelen in dit tijdschrift te openen met een over het Instituut van Actuaries, te Londen. Daarin gaf ik, zoowel over het ontstaan en de inrichting, als over den aard van dat lichaam eenige mededeelingen, terwijl ik over den Actuary, en wat er van hem gevorderd werd, meer uitvoerig sprak. Sedert heeft zich het Instituut in eene hoogst eervolle onderscheiding mogen verheugen: het verkreeg nl. een "Royal Charter of Incorporation."

Deze gebeurtenis is zeer zeker van genoegzaam belang, om mij te veroorloven haar hieronder nader toe te lichten, en tevens het Instituut en den Actuary, in verband daarmede, andermaal tot een onderwerp van bespreking te maken. Daardoor zal ik ook in de gelegenheid zijn om aan te vullen wat aan een goede behandeling daarvan wellicht nog ontbrak.

\section{I.}

Reeds spoedig nadat het Instituut in 1848 was opgericht, werd de verkrijging van een "Charter of incorporation" ter sprake gebracht, en zelfs in het eerste nommer van het Journal (September, 1850) of, zooals het toen werd genoemd, Assurarce Magazine, een conceptwet gegeven, aan wier memorie van toelichting ik de volgende opmerkingen ontleen.

"De vorming van het Instituut heeft ongetwijfeld in hoogen graad zoowel de beoefenaars van het vak, als hot publiek die 
bescherming verleend, welke beiden in hunne wederkeerige betrekking tot elkaar noodig hadden. De bloote vermelding van de namen van zijn leden zal in het vervolg voldoende zijn, om althans het grootste gedeelte van hen, die werkelijk tot ons beroep behooren, te doen kennen, terwijl bovendien het bestaan van het Instituut als georganiseerd lichaam, hoogstwaarschijnlijk onkundige en onberoegde personen beletten zal, een naam aan-en werkzaamheden op zich te nemen, waartoe noch hunne opvoeding en opleiding, noch hunne bekwaamheden hun eenig recht geven. Doch er wordt nog meer vereischt! Dat het Instituut spoedig al de thans levende mannen van het vak in zich zal opnemen, en dat het daarna een nienw geslacht van zelfs nog meer bevoegden dan tot hiertoe optraden, zal uitzenden, lijdt weinig twijfel. Doch daarvoor moet het voortbestaan van het Instituut zelf verzekerd, en het indringen van ongeschikte personen in ons rak, waarop toch nog altoos een kans, hoe klein ook, bestaat, volstrekt belet worden. Dit $\mathrm{nu}$, het is duidelijk, kan alleen door de hulp en onder het zegel van de Wetgevende Macht geschieden."

In de conceptwet zelf werd in de eerste plaats voorzion in de inschrijving, zonder kosten, van de namen van alle erkende deskundigen, hetzij leden van het Instituut, of niet. Verder bevatte het de "incorporation" zelf van het Instituut met al zijne destijds van kracht zijnde wetten en reglementen. Hierna volgde de wijze van benoeming en inschrijving der toekomstige leden en de voorwaarden van hunne toelating tot de praktijk, benevens de strafbepaling op het aannemen van den titel van Actuary, en het verrichten van werkzaambeden als zoodanig, door onbevoegden. Eindelijk, en ten slotte, gaf de conceptwet een uiteenzetting van den waren aard en de juiste beteekenis van het bedrijf van den Actuary.

Dit wetsontwerp schijnt tegenkanting ondervonden en geen gelukkig lot gehad te hebben; althans weinig of niets werd er later van vernomen.

Niet zeer lang daarna, in April 1853, hielden de leden van het Instituut een buitengewone algemeene vergadering, en wel naar aanleiding van eene door het Huis der Gemeenten benoemde Commissie tot onderzoek van Verzekeringsinstellingen en van de wet van 1844, op welke vergadering drie besluiten genomen werden, waaronder het volgende: $„$ De Vergadering is van oordeel, dat geen wet op de levensverzekering-maatschappijen van blijvend nut kan zijn, zoo die niet bewijzen van onbesprokenheid en bekwaamheid eischt van hen, die tot de praktijk van Actuary worden toegelaten." 
Wat de genoemde Commissie betreft, deze bracht een verslag uit, waarvan het slot aldus luidde: "Uwe Commissie eindigt haar Verslag met de opmerkzaamheid te vestigen op dat gedeelte van de ingekomen getuigenis, hetwelk de vorming en vestiging van een bij de Wet erkend Genootschap van Actuaries aanbeveelt, op grond dat daardoor de wetenschap zou gebaat - en bewijzen van bekwaamheid aan hen zouden afgegeven kunnen worden, die tot het uitoefenen van de praktijk van Actuary inderdaad bevoegd zijn. Mocht eenige poging gedaan worden, om het Parlement tot het verleenen van eene akte van incorporatie aan zoodanig genootschap te bewegen, dan acht de Commissie dat eene zaak, ten volle der overweging waard, doch tevens, dat vóbr een afdoende maatregel wordt genomen, nadere inlichtingen hoog noodig zullen zijn. Een groot verschil van meening toch betreffende dit onderwerp heerscht er onder de Actuaries zelven"

Deze laatste zinsnede, welke de hoogste bevreemding moet wekken, als men alleen het Instituut in het oog houdt, vindt hierin hare verklaring, dat bij de oprichting van het Instituut van Actuaries in 1848 , eene zeer kleine minderheid, die voor eene openlijke behandeling van zaken en het geven van vakonderwijs niet gunstig gestemd schijnt te zijn geweest, zich had afgescheiden en gevormd tot eene afzonderlijke vereeniging, onder de benaming van the Actuaries' Club. Het was van deze vereeniging; dat steeds het verzet tegen eene wettelijke erkenning van het Instituut uitging. Tot op hare opneming in het Instituut (zie hieronder) hield zij geregeld hare vergaderingen, waarop zaken van gemeen belang geheim behandeld werden.

De moeilijkheid om, met het oog op de wetgeving, te bepalen wie al dan niet als een Actuary te beschouwen is, kwam, sedert het bedoeld Verslag werd uitgebracht, minstens tweemaal in Engeland voor; het eerst bij de zamenstelling van de "Life Assuranco Companies' Act" van 1870 , en daarna bij die van de „Friendly Societies' Act" van 1875. In geen van de beide gevallen deed de Wetgever eene poging om die moeilijkheid uit den weg te ruimen, en wel hoofdzakelijk om de in het slot van het genoemd Verslag aangewezen reden.

En daar die reden, voor een gedeelte althans, bleef bestaan, zoo bleef ook het Instituut, niettegenstaande het steeds meer en meer in aanzien steeg en in invloed toenam, gedurende zeer vele jaren verstoken van hetgeen reeds, van den aanvang af, door zijne stichters op goede grondon werd gewenscht. Eindelijk, in 
het voorjaar van 1882 , kwam de "incorporation" van het Instituut in de vergaderingen van den Raad opnieuw ter sprake, en werd besloten een voorstel tot aanbeveling daarvan bij de Gewone Jaarlijksche Vergadering in te dienen. Het werd dan ook op de vergadering van den 3 den Juni daaraanvolgende ter tafel gebracht, en met algemeene stemmen angenomen. Tevens werd de Raad verzocht en gemachtigd, de noodige stappen tot het verkrijgen van een "Charter of Incorporation" te doen.

En die stappen werden gedaan den 15den September 1882 daaraanvolgende, doch hadden vooreerst niet het gewenschte gevolg, voornamelijk alweder door den tegenstand van the Actuaries' Club. Ten laatste echter kwam er een schikking en overeenkomst tot stand, en het Instituut van Actuaries, incorporated by Royal Charter" op den 29sten Juli 1884."

\section{II.}

De hoofdtrekken van het Charter zijn de volgende:

Omschrijving van het doel en den werkkring van het Instituut van Actuaries (*).

Aanwijzing van het hooge gewicht van het beroep van Actuary, en van de veel en velerlei omvattende opleiding, die daarvoor vereischt wordt.

Erkenning en in het licht stelling van het feit, dat reeds belangrijke en nauwkeurig omschreven plichten den Actuary zijn opgelegd bij de „Life Assurance Companies'Act 1870", bij de Friendly Societies' Act 1875" en bij de voorafgaande wetten, welke op de "Friendly Societies" betrekking hebben.

Opnoeming van de gevallen, waarin, van 1852 af, het vertegenwoordigend karakter van het Instituut van Actuaries, en de positie welke zijne leden tegenover de publieke belangen innemen, door Regeeringspersonen, of Staatslichamen werkelijk erkend werd.

Verder overweegt het Charter:

dat het bedrijf van Actuary van zoodanigen aard is, dat daaraan zeer dikwijls belangrijke zaken door de Kanselarij van het Hooggerechtshof en door andere Rechterlijke en Administratieve Afdeelingen van den Staat worden opgedragen;

dat het Instituut van Actuaries ten doel heeft de verheffing van den stand van den Actuary, en wel door het geven van eene wetenschappelijke opleiding en door de onderlinge mede-

$\left({ }^{*}\right)$ Zie •Economist” 1877, blz. 403. 
deeling en verspreiding van wetenswaardigheden betreffende de praktijk, zoodat hierdoor ook eene meer volkomen vervulling van plichten, welke de hoogste belangen raken, wordt verkregen;

dat het Instituut van Actuaries reeds eene groote hoeveelheid gegevens betreffende de sterfte-statistiek verzameld en publiek gemaakt heeft, en daaruit onderscheidene tafels heeft doen berekenen en in het licht geven, welke tafels bij de Levensverzekeringmaatschappijen in Engeland en andere landen een uitgestrekt gebruik hebben gevonden;

dat het Institunt van Actuaries reeds door de uitgaaf van zijn orgaan, bekend onder den naam van het Journal of the Institute of Actuaries and Assurance Magazine, hetwelk voor het grootste gedeelte bestaat uit bijdragen van zijn eigen leden, gedurende de laatste twee en dertig jaar hoogst belangrijke inlichtingen, zoowel van theoretischen als van practischen aard, heeft gegeven en verspreid, waarvan het gevolg is geweest, dat genoemd Journal zoowel in Engeland als in andere landen, de leidende gids is geworden betreffende alle zaken, welke met het beroep van den Actuary in verband staan;

dat het Instituut van Actuaries reeds ten gebruike van Actuaries en van anderen een Handboek der Beginselen van Interest- en Renten-rekening heeft doen schrijven en uitgeven, vormende dit het eerste gedeelte van een volledige Handleiding tot de Wetenschap van den Actuary;

en dat het Instituut van Actuaries reeds door het geven van klassikaal onderwijs van den meest degelijken aard, en zijn daarop gebaseerd stelsel van examens, met wier afneming het zich gedurende de laatste twee en dertig jaren heeft belast, grootelijks heeft bijgedragen tot een goede behartiging van zaken van het allerhoogste gewicht.

Hierna wijst het Charter op de omstandigheid, dat bet verleenen van een "Royal Charter" het Instituut nog beter in staat zal stellen aan zijn bestemming te beantwoorden, doordien het aan zijne leden, naast de oplegging van een zwaarder taak, ook grooter voorrechten zal waarborgen.

$\mathrm{Na}$ het bovenstaande, dat als het ware de inleiding vormt, en de verleening van het Charter motiveert, wordt tot de ${ }_{n}$ incorporation" zelf, waarvan ik de termen mijn lezers besparen zal, overgegaan. Daarop volgen de voorschriften en bepalingen, waaraan het Instituut in het vervolg zich zal hebben te houden, en die vervat zijn in 46 artikelen, verdeeld in 16 hoofdstukken. 
Het 10 hoofdstuk, getiteld „Preliminary", bevat de omschrijving of beteekenis van de in de volgende hoofdstukken gebezigde benamingen.

Het 2e hoofdstuk, tot titel voerende „The Council", handelt over den Raad, zijne rechter en verplichtingen, de wijze van benoeming zijner leden, benevens de namen van hen, die voorloopig den Raad zullen uitmaken, totdat een Raad zal gekozen zijn volgens de bepalingen eener Wet, op voorschrift van het Charter (zie hieronder) te maken.

De Raad is het hoofd van het Instituut en wordt uit de Fellows gevormd.

Het 3e hoofdstuk heeft tot opschrift „President and Vice-presidents", en omschrijft de wijze van benoeming van den President en de Vice-Presidenten, die altoos uit de Fellows zullen moeten worden gekozen. Tot eersten President wordt voorloopig benoemd de heer Thomas Bond Sprague.

Het 4e hoofdstuk noemt onder het hoofd "Classes of Members", in de volgende rangorde, de verschillende soorten van leden op:

(1) Fellows.

(2) Associates.

(3) Studenten.

(4) Eereleden.

(5) Correspondeerende leden.

Het 5e hoofdstuk handelt, onder den titel van ${ }_{n}$ Fellows", over deze klasse van leden, en verklaart tot Fellows van het "Incorporated" Instituut: 10 hen, die Fellows van het Instituut van 1848 waren op den datum van het Charter en 20 de leden van "the Actuaries Club." Verder omschrijft het de wijze en de voorwaarden van hunne benoeming.

Het $6 \mathrm{e}$ hoofdstuk heeft tot titel „Associates" en handelt over deze klasse van leden, en de wijze van hunne benoeming.

Het $7 \mathrm{e}$ hoofdstuk wijst onder het opschrift van ${ }_{n}$ Students", eene geheel nieuwe klasse van leden $\mathrm{nl}$. de Studenten aan, en bepaalt dat nà den datum van het Charter de benoeming van leden, tot deze klasse behoorende, zal geschieden volgens de te maken Wet.

Het $8 \mathrm{e}$ hoofdstuk handelt over de "Honorary Members" (Eereleden) en het $9 e$ over de „Corresponding Members" (Correspondeerende leden) en de wijze van hunne benoeming.

Het 10e hoofdstuk, tot titel voerende „Examinations", bepaalt dat de door het Charter geëischte examens zullen gehouden worden 
op de wijze en de tijden en onder de voorwaarden als de Raad zal voorschrijven.

In het volgende of 11e hoofdstuk wordt onder het hoofd "Age" de ouderdom aangewezen dien men moet hebben bereikt, om tot Fellow te kunnen worden benoemd. Deze is 21 jaar.

Het 12e hoofdstuk verleent onder het hoofd "Decision of Council on Qualifications" aan den Raad de eindbeslissing omtrent de toelating van candidaten tot de verschillende klassen van leden, terwijl het volgende, of 13e hoofdstuk, onder den titel van "Subseriptions" de door de leden te storten bijdragen (waarvan de Eereleden en Correspondeerende leden zijn vrijgesteld) bepaalt.

Het 14e hoofdstuk, getiteld: „Rights of Members", wijst voor elke klasse, voornamelijk met betrekking tot de wijze van stemmen, de rechten der leden aan. De Fellows mogen de initialen F. I. A. - de Associates de initialen A. I. A. achter hun naam plaatsen. Alle Fellows zullen op de algemeene vergaderingen zoowel aan de discussies, als aan de stemming kunnen deelnemen. Evenzoo de Associates, met deze uitzondering evenwel, dat zij over de verkiezing, uitsluiting of schorsing van Fellows niet zullen mogen beraadslagen of stemmen.

De Studenten zullen aan de discussies mogen deelnemen, doch niet tot stemmen gerechtigd zijn, uitgenomen in die gevallen, welke in de te maken Wet zullen worden vermeld.

Eereleden en Correspondeerende leden zullen, onder de voorwaarden, door de te maken Wet vast te stellen, tot het bijwonen der algemeene vergaderingen het recht hebben, doch niet mogen stemmen.

In het 15e hoofdstuk, tot titel hebbende "Cesser of Membership", wordt bepaald, dat zij, die om welke reden dan ook, ophouden lid van het Instituut te zijn, geene rechten zullen kunnen doen gelden op de eigendommen van het Instituut.

In het $16 \mathrm{e}$ en laatste hoofdstuk eindelijk wordt onder het hoofd "Bye Laws", over de te maken Wet, en over de wijze, waarop zij aan het oordeel en de goedkeuring van de leden zal worden onderworpen, en over de voorwaarden van hare in werking treding, gesproken. Deze Wet zal o. a. nauwkeurig hebben te regelen: de verkiezing en toelating van de verschillende klassen van leden van het Instituut; de wijze van bijeenroeping en de tijd en plaats van de Algemeene en Buitengewone vergaderingen van het Instituut, de wijze van stemmen en de leiding der werkzaamheden; de rechten en voorrechten van de verschillende klassen van leden 
van het Instituut; de omstandigheden waaronder, en de wijze waarop het lidmaatschap verloren gaat; het beheer der geldmiddelen en der eigendommen van het Instituut, enz. enz. Tevens bepaalt het Charter, dat geene door het Instituut gemaakte wet van kracht zal wezen, dan nadat zij, na bij den Geheimen Raad der Koningin te zijn ingediend, door dezen zal zijn goedgekeurd.

III.

Het Charter eindelijk verkregen zijnde, benoemde de Raad oumiddellijk een Comité, en droeg daaraan de opstelling der laatstbedoelde Wet op. Dit Comité, waarin de Raad gezorgd had, elke richting uit eigen boezem op te nemen, vergaderde gedurende verscheidene maanden, elke veertien dagen, en overwoog ieder bijzonder punt van verschil dat zich opdeed, met de meeste nauwgezetheid. Hierna legde het de resultaten van zijne overwegingen in den vorm van een Conceptwet, bij den Raad over, die na har te hebben onderzocht en goedgekeurd, in den loop van Maart 1885, aan ieder lid van het Instituut een gedrukt exemplaar daarvan toezond, onder bijvoeging van het verzoek, dit met eventueele opmerkingen voorzien, vóór den 15den April daaraanvolgende aan hem te willen terugzenden.

Verscheidene bemerkingen, die voor een aanzienlijk gedeelte verbeteringen bleken te zijn, kwamen op deze wijze bij den Raad in, die na enkele kleine tegenstrijdigheden verwijderd en van het Concept een goed samenhangend geheel gemaakt te hebben, het den 10den October 1885 op eene Buitengewone algemeene vergadering van het Instituut den leden voorlegde, met dezen gunstigen uitslag, dat het, staande die vergadering, zonder discussie, en met algemeene stemmen aangenomen werd.

Do Wet bestaat, behalve uit een voorwoord, dat het doel en den werkkring van het Instituut aanwijst, uit 90 artikelen, over 12 hoofdstukken verdeeld. Zij handelen over den Raad, en zijn rechten en verplichtingen; de Bestuurders van het Instituat, hunne rechten, plichten en werkkring; de verschillende klassen van leden, de voorwaarden van toelating, wijze van benoeming, en ieders bijzondere rechten en verplichtingen, de examens en de te storten gelden; de schorsing van leden; de gewone en buitengewone algemeene vergaderingen; de veranderingen of wijzigingen in de Wet; en de verantwoordelijkheid van den Raad en de Bestuurders van het Instituut. 
Het eigenlijk kenmerk der Wet is, dat zij in de onderdeelen en zeer nauwkeurig en uitvoerig omschrijft wat het Charter zelf slechts in breede trekken aangeeft.

Vraagt men nu of er door de verkrijging van het ${ }_{n}$ Royal Charter of Incorporation", en door de invoering der nieuwe Wet, eene wezenlijke verandering is gekomen in de beteekenis en de inrichting van het Instituut van Actuaries, dan moet daarop toestemmend worden geantwoord. Het heeft toch het particulier karakter, dat het nog gedeeltelijk aankleefde, er geheel door verloren, en staat thans daar als een bij de Wet erkend wetenschappelijk lichaam en als de vertegenwoordiger van de Actuaries van het Vereenigd Koninkrijk. Doch welke nieuwe plichten het, ten gevolge van die verandering, te vervullen - welke maatregelen het tot bescherming van het publiek tegen den kant van onbevoegden, die zich als actuaries opwerpen, te nemen - en welke tucht het over de leden van het Instituut uit te oefenen zal hebben, ziedaar eenige vraagpunten uit de zeer vele, waarvan de beantwoording zoo dadelijk niet kan worden gegeven. Dit echter staat vast, dat het publiek in het vervolg niet meer mistasten kan waar het wil weten wie het recht heeft zich Actuary te noemen, en wie niet. Een Actuary is een Fellow van het Instituut van Actuaries (*) en niemand anders zal zich dien titel mogen aanmatigen. Ook zal natuurlijk de praktijk van den Actuary, overal waar die valt binnen de reeds door verschillende wetten gegeven voorschriften, in Engeland voortaan alleen door een der Fellows van het Instituut mogen worden uitgeoefend.

Eene der gewichtigste wijzigingen, die verder zoowel het Charter als de nieuwe Wet van het Instituut in de positie van den Actuary hebben teweeggebracht, is deze, dat de Actuary door de Wetgeving nu niet meer beschouwd wordt als te zijn, hetzij blootelijk, hetzij noodzakelijk, een der bestuurders van eene verzekering-maatschappij, maar dat hij door haar, en dit in de eerste plaats, erkend wordt als de bevoegde en geleerde beoefenaar van een wetenschappelijk vak. Dat het omgekeerde het geval zou kunnen wezen, schijnen de voormalige leden van de "Actuaries' Club" aanvankelijk te hebben gevreesd.

Eene tweede voorname wijziging, en dit in de inrichting zelf van het Instituut, bestaat in de invoering van eene geheel nieuwe

(*) Of vau de Faculteit vau Actuaries in Schotland. (Zie "Economist 1877" blz. 414.) 
klasse van leden, nl. van die der Studenten. Oorspronkelijk was het de bedoeling, dat de Associate de Student zou zijn $\left({ }^{*}\right)$, doch de ondervinding van het Instituut heeft bewezen, dat daaraan niet altoos werd voldaan, en dat personen met geen ander doel als Associates verzochten te worden toegelaten dan om het A. I. A. achter hun naam te mogen plaatsen en zich hierdoor uit te kunnen geven als in staat en bevoegd tot het maken van deskundige berekeningen, voornamelijk ten dienste van "Friendly Societies." Dit misbruik zal nu niet meer kunnen voorkomen, omdat men voortaan eerst, na als student door het Instituut te zijn ingeschreven, de bij de Wet gevorderde examens zal moeten hebben afgelegd, alvorens tot Associate te kunnen worden bevorderd.

Wat deze examens betreft, daarvan zal, gedurende de eerste drie jaren na den datum van het Charter, een candidaat-associate alleen dàn kunnen worden vrijgesteld, wanneer de Raad daartoe, op grond van de bijzondere verdiensten van dien candidaat, termen mocht vinden. In dit geval behoeft ook zoodanige candidaat niet noodzakelijk student to zijn geweest.

$\mathrm{Na}$ verloop der bovenbedoelde drie jaren worden de examens bijna altoos verplichtend. Ik zeg "bijna altoos", omdat ook dan nog de Raad, bij meerderheid van het volle aantal stemmen, een candidaat, uithoofde van gebleken bekwaamheden op het gebied der levensverzekering-wetenschap, van die examens vrijstellen kan.

Zal dus de Associate der toekomst zeer verschillen van den Associate van het heden, tot op zekere hoogte zal ook de Fellow van gisteren een ander zijn dan zijn ambtsbroeder van morgen. Aan dezen laatsten toch zullen eenigzins hoogere eischen worden gesteld dan die, waaraan vroeger moest worden voldaan. De Wet van het Instituat geeft nl., voor het tijdsverloop van de eerste vijf jaren na den datum van het Charter, als de voorwaarden van toelating tot de klasse der Fellows op: dat de candidaat in alle examens van het Instituut moet zijn geslaagd; dat hij de praktijk van Actuary gedurende tien jaren in het Vereenigd Koninkrijk of in zijne Kolonien moet hebben uitgeoefend, en dat hij de Actuary of Assistent-Actuary moet zijn van eene levensverzekering-maatschappij of van eune dergelijke inrichting, of de Actuary van eenig Departement van den Staat. Zijn de bedoelde vijf jaren verstreken, dan worden de eischen nog strenger, en kunnen candidaten, die voor het overige aan een der laatstgenoemde eischen beantwoorden,

(*) Zie "Econonist 1877" biz. 403: 
alleen bij wijze van uitzondering, en dit op grond van buitengewone verdiensten, van de examens worden vrijgesteld.

Het feitelijk resultaat van een on ander zal zijn, dat het volgend geslacht van Actuaries nitsluitend uit hen zal bestaan, die het diploma van het Instituut door goed afgelegde examens verkregen hebben. Of dit in alle opzichten een gewenschten toestand zal opleveren, is echter nog zeer de vraag. In Engeland zelf althans heeft men daaromtrent reeds twijfel geopperd en de meening vooropgesteld, dat de tot nu toe gevolgde regel, die ook de opneming van mannen van gezag en hooge positie in de verzekeringswereld onder de leden van het Instituut toeliet, nog zoo slecht niet was. Doch het Comité, dat de nieuwe voorwaarden van toelating opstelde, had zich daaromtrent aan de voorschriften en bepalingen van het Charter te houden.

IV.

Wie dus Actuary is, en een wettig - en in het vervolg uitsluitend recht heeft zich zoo te noemen, heb ik in het voorgaande aangewezen: het is een Fellow van het Instituut van Actuaries. Wat een Actuary is, en wat hij doet, heb ik uitvoerig uiteengezet in mijn meergenoemd opstel in de Economist van 1877. Toch geloof ik, dat het niet overbodig zal zijn hier nogmaals op dit laatste punt, zij het ook in eenigszins andere bewoordingen, terug te komen. Behalve door den wensch, reeds in den aanvang van dit artikel geuit, om het vroeger gezegde an te vallen, word ik daartoe ook gedreven door de overweging, dat het mij dikwijls in mijne langdurige praktijk van Actuary gebleker is, dat personen, anders hoog staande in kennis en ontwikkeling, eerst na eene omstandige verklaring van mijne zijde, zich een klaar denkbeeld van den aard van mijne werkzaamheden vormen konden, en dat ik weder anderen heb ontmoet, die den werkkring van den Actuary tot het wiskundig departement van eene levensverzekering-maatschappij beperkt waanden, en daarbij meenden, dat men met een weinig mathematische kennis en een formulenboek daarvoor al meer dan voldoende was toegerust.

Wat men oorspronkelijk onder het woord, actuary" verstond en welke beteekenis men or later aan hechtte, heb ik in mijn meergenoemd artikel medegedeeld. Een "actuary" heette daarin te zijn: " een persoon die geleerd had de waarschijnlijkheidsrekening toe te passen op de arangelegenheden des levens." Deze bepaling 
komt mij echter $n u$, en de reden zal zoo aanstonds blijken, zoowel onvoldoende, als niet geheel nanwkeurig voor.

Wil men zich, naar mijne opvatting althans, den Actuary in zijn ware positie en volle kracht voorstellen, dan denke men zich den reelzijdig ontwikkelden geleerde, die zich niet tusschen zijn boeken verborgen of besloten houdt, om zich met bloot theoretische en voor het oogenblik van geen nut zijnde bespiegelingen bezig te houden, maar die geregeld zijn cel verlaat, om zich in de woelige wereld te begeven, en daar met de nooden en behoeften van zijne medemenschen bekend te worden; en die zich met geen ander doel weder in zijne cel terugtrekt, dan om wat hij daarbuiten waarnam, daarbinnen al rekenende, in cijfers om te zetten. In den compleeten actuary (als $i k$ mij zoo eens mag uitdrukken) zijn twee zeer van elkander verschillende persoonlijkheden tot een harmonisch geheel vereenigd: nl. de geleerde mathematicus en de man van zaken. De stroefheid der wiskunkunstige wetenschappen, die altoos vraagt naar het bexijs, en de wel eens gevaarlijke losheid van den handelsman, zij zijn beide verdwenen bij deze gelukkigste aller combinaties, waarin juistheid van redeneering zich aan eene breede opvatting, en de nauwgezetheid van den onderzoeker en den rekenaar zich aan het initiatief van den ondernemer paren. Kortom, een man van het Studeervertrek, en tevens een man van het Bureau, het Archief, het Kantoor, de Beurs en het Salon: ziedaar den Actuary!

Evenwel, en het is goed het niet te verzwijgen, de samensmelting van inderdaad heterogene bestanddeelen is niet altijd gelukt, en vooral niet in die gevallen, waar men van wiskundigen van professie actuaries maken wilde. Zoo zegt A. H. Bailey, als President van het Instituut, in zijn openingsrede van den 29sten November 1880: "some very remarkable mathematicians, academic and non academic, have been tried and failed," on in zijn openingsrede van 28 November 1881: the attempt to incorporate the professor of mathematics with the business man has not generally succeeded." En hij voegt er bij: ${ }_{n}$ an actuary should be a man of general culture, with a knowledge both of books and men, and the more he has of both, the better."

Inderdaad, hierdoor zal hij des te beter zijn eigenaardige taak kunnen vervulleu. De Actuary toch heeft zich bezig te houden met al die betrekkingen tussehen de menschen, welke maar eenigszins op geld waardeerbaar zijn. De physieke, en ook voor een deel de moreele beteekenis van het Geboren-worden, Huwen en 
Sterven, van deze drie Hoofdmomenten van het bestaan van den mensch, zij kunnen door cijfers, door een getal worden voorgesteld, en dit getal moet de Actuary weten te bepalen. Bij Ziekte of Ongeluk staat, nevens de hulp vall den man der geneeskundige wetenschap en de troost der zijnen, den patient een Cijfer voor oogen, dat of dreigend, of helpend zal zijn, maar dat in beide gevallen de Actuary hem zal kunnen zeggen. De huishouding van den eenling, zoowel als die van den Staat, zij wentelen zich beide om één spil, verschillend in grootte, maar gelijk van aard: het geld, en het is de Actuary alleen, die met juistheid zal weten op te geven het maximum van genot tegenover het minimum van pijn, of de grootste ontvangst tegenover de kleinste uitgaaf, omdat hij alleen alle factoren der berekening kent. De Actuary is daarom de Rekenaar bij uitnemendheid, de Meester in de Politieke en Sociale Rekenkunst.

In overeenstemming met het zoo even gezegde, merkte Lord Overstone, een der Eereleden van het Instituut, en dit reeds bij gelegenheid van de groote Wereldtentoonstelling te Londen, in 1881 , op :n that the actuaries, as he understood it, are engaged in endeavouring to investigate the varied and complicated phenomena of the active life which surrounds them, and especially as far as they have reference to the casualities, often miscalled accidents, which affect them in their persons and properties; and their object is, out of the surrounding and apparent confusion, to educe, if possible, something like order and regularity; and from their views of that order and regularity, to arrive at some knowledge of the laws by which that apparent confusion was regulated, and to found regulations and institutions which would contribute to the safety of society, to the progress of the best interests of mankind, and to tho advancement of civilization."

De Actuary is dus de man, die in's volle Menschenleben linein greift, om - er eijfers uit op te delven. Alles geordend zijnde volgens Maat, Getal en Gewicht, is hij het, die zoowel het menschelijk als het maatschappelijk leven in hunne oorzakelijkheid en wisselwerking naspeurt, en wat dauruit met noodzakelijkheid moet volgen, in getallen weet weer to geven. Veelomvattend is daarom zijn werkkring. Alle vraagstukken, welke ook, die tot uitkomst eene geldsom, eene geldswaarde moeten opleveren, zijn hem het best toevertrouwd, omdat hij alleen geleerd heeft ze op voldoende wijze op te lossen. In Engeland, waar hij het eerst erkenning en waardeering heeft gevonden, staat hij dan ook in 
hoog annzien, noemt men hem den wetenschappelijken financier, en breiden zijn gezag en invloed zich steeds uit; terwijl hij verder overal, waar de beschaving eene zekere hoogte heeft bereikt, en de wetenschap, in het bijzonder de mathematische, in het dagelijksch leven begint door te dringen, te voorschijn zal moeten komen. En onontbeerlijk zal hịj dáár worden, waar de levensverzekering, die schoone vrucht van statistiek en wiskunde, van theoretisch onderzoek en praktisch streven, in de maatschappij ontluikt. Zonder hem een gevaar, kan zij eerst mèt en doòr hem tot een weldaad worden.

Maar is de levensverzekering zonder hem niets, omgekeerd zal hij haar veel te danken hebben. Daarom zeide de heer A. H. Bailey terecht, in zijn bovengenoemde openingsrede van 28 November 1881: "The most fitting, nay almost the only place for the training of such a scientific financier is the office of a life assurance society. Actuarial work scems to be on the increase, but the public refuse to employ any but those who have a recognised position with a public company."

Doch tot de theoretische en practische beoefening der levensverzekering-wetenschap, hoewel deze een der schoonste parels is aan zijn kroon, bepaalt zich het doel van den Actuary geenszins. Zijn werkkring is, wij zagen het reeds, van een veel grootscher omvang. De beste wijze van Sparen; de Verzekering tegen de gevolgen van Ongeval, Ziekten en Ongeschiktheid tot den arbeid; de Verzekering op Huwelijkskansen; de berekening van de hoegrootheid van Schadeloosstellingen; stelsels van Belasting, waaronder voornamelijk de Inkomsten- en de Verteringbelasting, en de Progressieve belasting; Premien voor de verzekering op het leven van niet volkomen gezond zijnde personen, en voor de verzekering op het leven van personen, in wier familie jicht of tering voorkwam; Premien voor de verzekering op het leven van Officieren bij de Land- en Zeemacht, welke premien zoowel in tijden van Oorlog als van Vrede zouden moeten gelden, en berekend dienen te worden uit de onder hen waargenomen sterfte gedurende een zeer lang tijdsverloop; eindelijk de Werklieden-verzekering in al de verschillende vormen die men haar zal kunnen geven: ziedaar zoo vele voor de vuist opgenoemde onderwerpen, die tot het gebied van den Actuary behooren, en òf reeds eene geheele of gedeeltelijke oplossing gevonden hebben òf dringend daarop wachten. Ja, dit gebied is zelfs zoo uitgestrekt, en wat daarop voorkomt van zoo verschillenden aard, dat ook reeds hier 


\section{7}

eene verdeeling van den arbeid, voornamelijk waar het geldt de wetenschap vooruit te brengen, heeft plaats gehad, zoodat men (in Engeland altoos) aan de eene zijde Actuaries heeft, die eene bijzondere studie maken van de theorie, en die de methoden van berekening steeds zooveel mogelijk zoeken te verfijnen en te verscherpen, en aan de andere, Actuaries, die zich meer toeleggen op het leveren van practische en algemeen bruikbare resultaten, als daar zijn: het berekenen en uitgeven van allerlei soorten van tafels. Ook zijn er, die zich bij voorkeur bezig houden met de Statistiek en wat daartoe behoort, en weer anderen, die zich met roorliefde toeleggen op de beoefening van de Geschiedenis van al datgene wat tot de wetenschap van den Actuary gerekend wordt.

En deze wetenschap, ik wensch hier nogmaals met nadruk op te wijzen, omsluit ook de geheele Politieke en Sociale Rekenikunde. Dit nu wil heel wat zeggen. Die Rekenkunde bevat toch alles wat op Interest- en Rente-rekening, Koersrekening, Loterij- en Premieleeningen, Blooten eigendom en Vruchtgebruik, Handels. en Koop. mansrekenen, Verzekering, enz. enz. betrekking heeft. En nu is het mijn innige overtuiging, dat er in de maatschappelijke huishouding veel, zeer veel is wat anders en beter zou kunnen berekend worden. Er bestaat voor een deel door het gemis, en voor een deel door het niet raadplegen van Actuaries, zeer stellig veel misrekening hier en daar. Behalve door hetgeen openlijk voor elk Actuary die het wil narekenen, blootligt, is mij dit persoonlijk ook nog gebleken door voor bijzondere personen of inrichtingen gemaakte berekeningen en naar aanleiding daarvan gedane onderzoekingen en gehouden gesprekken. Gebrek aan die juistheid van berekening waarnaar de Actuary streeft, en waarin hij zijn roem stelt, en zonder welke eene rechtvaardige verdeeling van baten en lasten onmogelijk is, valt waar to nemen van laag bij den grond tot zeer hoog opwaarts. Daarom zou ik, waar de hoogstrerdienstelijke en eminente Actuary, de heer Th. B. Sprague, thans President van het Instituut, in zijn openingsrede van 26 November 1883 aan het slot daarvan opmerkt, dat ${ }_{n}$ hoewel uit een algemeen oogpunt misschien mag worden gezegd, dat het doel van de stichters van het Instituut geresumeerd wordt in den wensch, dat de Actuary de Directeur zal wezen van zijne Maatschappij, het beter is hetzelfde eenigszins anders uit te drukken en te zeggen, dat het de wensch is van het Instituut dat de Directeur van elke Verzekeringsmaatschappij een Actuary zal ECoN. 1886. 
zijn", - daaraan willen toevoegen: den blik hooger gewend. De loopbaan van den Actuary strekt zich uit voorbij de Directiekamer eener levensverzekering-maatschappij, en haar natuurlijk eindpunt is dáár waar de hoogste Fînanciekunst gerekend wordt haar zetel te hebben opgeslagen. En hoewel het nu in den aard der dingen ligt, dat niet allen, maar slechts weinigen, zeer weinigen, dat punt zullen kunnen bereiken, zoo zal het toch, mijns inziens, in de naaste toekomst, in het belang van Staat en Maatschappij, hoog noodig, ja, onvermijdelijk wezen, dat (en het wordt gezegd met de verschuldigde deferentie) elk Minister van Financien een Actuary zij. 